\title{
Impact of ESL Learners' Self-Esteem on Their Oral Proficiency
}

\author{
Shugla Mandokhail ${ }^{1}$, Fouzia Rehman Khan $^{1} \&$ Mehwish Malghani ${ }^{1}$ \\ ${ }^{1}$ Sardar Bahadur Khan Women's University, Quetta, Pakistan \\ Correspondence: Mehwish Malghani, Sardar Bahadur Khan Women's University, Quetta, Pakistan. E-mail: \\ mehwishmalghani@gmail.com
}

Received: November 21, 2017 Accepted: December 20, 2017 Online Published: February 10, 2018

doi:10.5539/ijel.v8n3p210

URL: http://doi.org/10.5539/ijel.v8n3p210

\begin{abstract}
This study attempted to investigate the relationship between ESL learners' Oral proficiency and their level of Self-esteem. The sample consisted of 30 students of Master studying English language at SBK Women's University Quetta Baluchistan. The data were gathered through two instruments: Rubric for ESL Oral Proficiency along with voice recording and the Rosenberg (1965) Self-esteem Scale. The technique applied was non participant controlled observation. To determine the relationship between ESL learners' Oral proficiency and their level of Self-esteem, correlational analysis was employed quantitatively. The findings revealed a significant positive relationship between the two variables and asserted Krashen's Affective Filter Hypothesis that an imaginary barrier of affective factors in learner prevents the learner from acquiring the target language.
\end{abstract}

Keywords: self-esteem, oral proficiency, language acquisition

\section{Introduction}

Second language acquisition (SLA) requires competence in all four basics kills: listening, speaking, reading and writing. This acquisition is not a mere mental process rather psychological factors play a vital role in leaner's success in learning, mastering and using a second language. Theorizing process of second language acquisition within solo sphere of cognitive domain may proves misleading in most of the conditions, unless the affective domain of learners is kept into consideration. That is why the study of language learners' characteristics known as "Individual differences" (IDs) has been the center of focus in second language studies for a long time. The term "Individual Difference" is a broad psychological jargon covering a wide range of human traits and characteristics but in a narrowest sense, from educational perspectives Cooper (2002) equates IDs or Individual Differences with personality and intelligence. While Dornyei (2006) opines that Individual Differences are the characteristics which make individuals unalike. They are those traits in respect of which humans are shown to psychologically differ from each other. In the context of SLA, Dornyei delineates the term Individual Differences to personality, ability and motivation, which the author further describes in terms of five personality variables; anxiety, self-esteem, creativity, willingness to communicate and learner beliefs.

Merriam Webster Dictionary defines self-esteem as one's confidence and satisfaction in self. Self-Esteem defined by Branden (1969), is the tendency in human personality to experience oneself as being praiseworthy and competent in coping with basic life challenges, is one of the most accepted definitions. Another well accepted definition is given by Coopersmith (1967) who confines Self-Esteem to the evaluation an individual makes and habitually maintains with reference to one's own self, which he may express by an attitude of approval or disapproval eventually determining the extent of his belief about self-capabilities, a sense of being significant, successful and worthy. According to Brown (1994) extrinsic and intrinsic affective factors contribute to the success of language learning and the improvement of pedagogy. In his notion, during learning a second language, those socio-cultural variables which results from experiences of a L2 learner by observing the two languages and their cultures are the extrinsic factors of affectivity and besides other intrinsic factors such as risk taking propensity, inhibition, anxiety and motivation, he asserts "self-esteem" as one of the essential personality factor that plays its role while any cognitive or affective activity takes place in a second language classroom. Brown classifies self-esteem into global, specific/ situational and task self-esteem where Global self-esteem stems out from the acceleration of inter- personal and intra- personal experiences with respect to external world, while specific self-esteem derives from the valuation that individuals make in a certain life events and task self-esteem deals with the assessments one would make of specific situation. Brown concludes that without some degree of immersion of self-esteem as a variable in L2 learning, no successful cognitive or affective performance could be yielded. 
Rosenberg (1965), renowned for his most commonly used self-esteem measurement scale refers to self-esteem as sum of the individual's thoughts and feelings with respect to own self as an object. He states that high self -esteem illustrates a sense of worthiness and feelings of respect of individuals about themselves for what they are, irrespective of what others may feel for them. This conception of Rosenberg implies a meaning that dealing with self-esteem may not lead a person to ego-centric behavior, rather the term refers to a balance view of self-worth by means of which any learning task can be carried out at ease. In the context of L2 language learning it can be proposed that ESL learners' belief about own self leads them to judge learning process and what learners feel in turn determines their behavior, ultimately affecting the way a learner approaches learning experiences as well as opportunities in order to future language learning. This either brings growth in the acquisition process or impedes it accordingly. Hence, in the context of L2 language learning it can be proposed that ESL learners belief about own self leads them to judge learning process and what learners feel in turn determines their behavior, ultimately affecting the way a learner approaches learning experiences as well as opportunities in order to future language learning. This either brings growth in the acquisition process or impedes it accordingly. If a learner visualizes themselves performing a language task successfully e.g., speaking a target language fluently and interactively, this strong mental image would help him in reducing negative beliefs and affirmative starting point in real learning situation. In the context of this discussion, acquiring second language Oral proficiency enables learners not only to nurture positive values and attitudes toward target community and increase their awareness of world-views but also demands the growth of positivity toward their own personalities.

Most of the times Competent ESL learners erroneously interpret their progress as awkwardly slow and esteem their selves low, ultimately they avoid opportunities such as debates, discussions, conversations, presentations and interviews required to excel their Language Oral proficiency. The purpose of the study is to investigate the effect of an ESL learner's level of Self-Esteem on his/her Second Language Oral Proficiency achievement.

\subsection{Hypothesis}

Self-Esteem and Language Oral Proficiency are positively correlated, such that ESL learners who have low level of Self-Esteem also have poor Oral Language Proficiency achievements and the ESL learners with high Self-Esteem have high Oral Language Proficiency achievements.

\section{Literature Review}

Researcher has found a concise array of valuable works available on the issue of self-esteem and its correlation with ESL Oral Proficiency. This chapter compiles an interesting set of studies and provides a review of the existing literature, a reliable discussion on Self-esteem's role in academic achievements as well as an association between Self-esteem and ESL Oral production, along with different models and strategies in the light of previous studies, as researcher herself desires to make an attempt for exploring an association between ESL learners' self-esteem and the area of oral language proficiency.

Nogueras \& Rosa (1996) mentioned that Self-esteem has been long the focus of study among educators, psychologists, sociologists and linguists. Educational Resource Information Center (ERIC) accounts for more than 12,000 entries related to the areas such as self-esteem, self-perception, self-concept and self-image whereas the American Psychological Association (Psy-CINFO) enlists over 92,000 entries of the same areas, among which 143 entries are entitled purely as self-esteem in relation with second language acquisition.

Dornyei (2006) regards Self-esteem as one of the fundamental individual's affective characteristics in educational psychology, yet no adequate works have been produced to it in SLA field. This might be due to the fact that self-esteem is closely related to the concept of self-confidence, which has been vigorously reflected in Applied Linguistics with respect to second language acquisition. Certainly self-confidence and self-esteem shares a mutual emphasis on individual beliefs in evaluating own attributes and abilities as a worthy individual person. In Brown's view self-esteem is probably the most persistent aspect of any human behaviour, however Carver et al.; termed self-esteem as an evaluative quality of one's self-image and self-concept.

Every individual has a self-concept though he may find it difficult to accurately describe his self-concept. Individuality is a combination of self-concept i.e., the way one would see his self and his personality. Self-concept is related to one's self-esteem and unless a sense of self-esteem is developed, an individual is unable to progress toward what Maslow calls self-actualization (Ritak, 2000).

Higgins (1996), claims that there are different types of selves such as actual self, possible self, ought self and ideal self. Defining Self-esteem becomes a complex variable if an attempt is made to differentiate between these varieties of self since self-esteem as a variable possibly may fluctuate depending on which self-function serves as a reference point for valuation. Therefore a same individual can simultaneously hold high, moderate or low 
levels of different types of self-esteem.

Rubio's (2007) offers a wealth of discussion about various closely related affective variables including self-esteem, self-concept, self-image, self-confidence, anxiety, willingness to communicate, language ego and integrative motivation in the history language learning and pedagogy. Negative behaviour stimulates learner's low expectations and every failure is seen by them as a confirmation of their low expectations and previous negative perceived self. Similarly Deutsch \& Solomon (1959) found that a negative valuation of self by others might be more satisfactory for an individual having low self-esteem than a high appraisal. Ehraman et al. (2003) and Dornyei (2006) advocate the need for self-acceptance a highest human priority, in the light of motivation theory. Brown (1994) studying self-esteem also explored concluded that self-belief and self- image tends to play a critical role in guiding and regulating one's behavior. Therefore he suggests that limited perceived beliefs can be reformed with the help of mental imagery as human feelings are closely related to their mental images including self-image. If learners visualize themselves performing a language task successfully e.g. speaking a target language fluently and interactively, this strong mental image would help him in reducing negative beliefs and affirmative starting point in real learning situation. In the context of language learning, Dornyei (2006) implies the same notion of "ideal selves" by coining the term as "Ideal $\mathrm{L}_{2}$ Self". As stated by him it is crucial for every learner to reduce the difference between actual-self and ideal-self. Ideal $\mathrm{L}_{2}$ Self is a powerful motivator in second language learning. Throwing light upon all these valuable studies, Rubio (2007) emphasis that focusing our attention on learners' self-esteem in a language class room may contribute to direct learners' energy towards productive language acquisition which they in particular circumstances consume in nonproductive identity beliefs making them divert from learning tasks and opportunities.

Norgueras \& Rosa (1996) explored the relation among self-esteem, self-evaluation and oral communicative language proficiency in ESL classroom at University of Puerto Rico. This research was based on three years descriptive case study of the first year students in one of the campus in that university. Krashen's Affective filter hypothesis served as theoretical foundation for the study. For the first variable i.e., oral proficiency in English language, Norgueras \& Rosa (1996) selected an adopted version of Bachman-palmer oral interview test while on the other hand Ramos-Perea self-report self-esteem instrument and Heyde (1983) self-esteem instrument were chosen for the second variable. Statistical outcomes computed with the help of Pearson Product Moment Correlation to express all potential pairing of the relationships amongst the learners' self-esteem in the ESL setting with levels of their oral proficiency indicated insignificancy of the relation but the qualitative analysis of the data obtained through Heyde (1983) self-esteem instrument revealed that learners with positive self-esteem scored high oral ESL proficiency. Besides the dissimilar outcomes in two different paradigms, it was concluded too that language learning environment in ESL classroom likewise influenced learners' variant levels of self-esteem. These results determined that learners though have high self-esteem yet they may possibly have different levels of self-esteem due to different language learning environments.

Speaking and listening are the two collaborative Language skills. Nunan \& Cartner (2001) put forward that where several studies have affirmed the significance of listening comprehension in authentic put for speech production, there many of them also have suggested that better input-output results cannot be attained without cautious attention to psychological factors, due to which learners usually scores variedly regardless of their expected grades and self-esteem is one of the overpowering issue concerning these variations. Demo \& Parker (1987) are also of the view that self-esteem and language learning in real situations are positively correlated where the strength of one variable directly affects and influences the other one. In the light of these deliberations, Hayati \& Ostadian (2008) investigated relation of self-esteem to listening comprehension of sixty intermediate EFL learners at S.T. Petroleum University of Abadan, Iran. Their selected population contained an equal ratio of male to female participants. TOEFL proficiency test (2005) and Coopersmith's standardized questionnaire were used as instruments. The collected data statistically showed .44 value of correlational coefficient of males' self-esteem in relation to their listening comprehension while .57 value of females' self-esteem and their listening comprehension and with the help of $\mathrm{T}$ test, $\mathrm{r}=.50$ was compute on the whole indicating a positive correlation between learners' self-esteem and their listening comprehension. The study hence revealed the fact that emotions and psychological factors have more influence on female learners than males and those females with high self-esteem tend to show better performance in learning tasks as compared to male learners. (Hayat \& Ostadian, 2008)

Heyde (1983) investigated the relation of three levels of self-esteem (global, specific/ situational and task self-esteem) to the 181 American learners' oral communicative language proficiency in French as their second language; whereby she explored self-esteem to be related positively with their second language oral proficiency. The participants were asked to evaluate their worthiness before and after their oral performance of using French in unplanned speech. The participants had to assess themselves upon to types of measures i.e., Errors and 
Comparison; where in Error Task self-esteem learners esteemed their selves on a general rating of errors that they thought they have made while speech performance and in Comparison Task self-esteem learners made evaluation by comparing their own performance with the performance of other class fellows that they had expected. Consequently, she found a relationship existing among all three types of self-esteem with oral proficiency; primarily task self-esteem was highly correlated to $\mathrm{L}_{2}$ oral communicative language proficiency. She hence agreed with Brown (1994) views that oral performance is strongly influenced by learners' global and task self-esteem.

Several models and theories have been postulated concerning a relation among personality variables and language achievement while on the other hand various researches have contributed in exploring a correlation among these personality variables and academic achievements. The extraversion-introversion dimension is the most researched personality aspect in language studies. In addition to such conceptual differences, the complexity of selecting the best measurement approach has also served as an obstacle for both linguists and psychologists. Accordingly, the application of the Big Five model and Myers-Briggs Type Indicator (MBTI) has frequently been used in L2 studies as a learning style measure. With present discussion, a worth mentioning among them is the Theory of Linguistic Self-Confidence (2001) by Richard Clement and his associates. On the basis of their findings, they stated that from motivational perspectives, linguistic self-confidence is a chief factor in multi lingual context to learn other community's language. Clement and his associates strengthened the applicability of the self-confidence construct by providing evidence that situations in which individuals communicate indirectly with L2 community members for instance through media (such as in case of English language), there self-confidence is a significant motivational factor in learning target community's language (Dornyei, 2005).

Rubio (2007) perceives language learning as a journey whereby every learner doesn't take the same route or same speed to reach desired target. He believes that language programs err by exciting learners to achieve native-like competence as their ultimate goal because when learners are compared to native speakers or they themselves compare their proficiency to native-level. As a result of such comparisons, learners inexorably come up short and they erroneously infer their progress as awkwardly slow, consequently contributing to their poor level of self-esteem. Therefore as models for language learners language professionals must prefer "functioning bilinguals within language communities" to native-speakers. This approach would make learners to appreciate themselves as more competent language learners and worthwhile in bilingual situations. Hence learners' feelings of self-esteem will profit more from realistic goals available to them. Similarly Howitz et al. (1986) highlight learners' self-esteem, and observe that it is obligatory to be aware of the fact that during language learning process a learner's feeling about own self may grow differently at different points. More advanced learners might not have higher levels of self-esteem in all cases, rather the more they advance, the more they become sensitive to the limitations in their language ability. He further point outs lack of self-esteem in learners to be influencing for language teaching. When advanced language learners with low self-esteem come to be language teachers, the experiences offered by them to their students, may possibly get limited due their low level of self-esteem. Rubio (2007) supports the encouragement of positive self-esteem in language classrooms. He suggests language counseling for successful second language acquisition to learners who can visit a counselor throughout any phase of their language acquisition either initial stage, or the finale point of their language studies. Language counseling would provide assistance to learners to set certain personal goals regarding language learning and would also help them in developing plans to reach these language learning goals. Generally the amount of proficiency needed to be achieved in a language classroom is seen limited in traditional school-based programs; therefore teachers must motivate the learners to be more autonomous and self-directed. The growth of autonomy and self-direction may itself be a source of self-esteem for many learners. Language counseling most notably is helpful for learners in such encouragements.

All of the Affective factors related to motivation such as defense mechanisms, anxiety, internal attitudes, self-esteem, self-regulation, self-management, beliefs and emotional intelligence play an essential role in stimulating or preventing learners' autonomy. Like students differ, teachers too vary in their teaching style, and preferred strategies. Ehrman et al. (2003) concludes that enabling learners to acquire as much as they can, it is indeed necessary to provide them with assistance, involving a program would help them to continue their learning process in a relatively stress-free and untroubled manner. This implies a meaning that providing learners with opportunity to learn in their preferred styles, instead of always outside of them would likely help the students but sometimes also help teachers in understanding the difference between a learner's and a teacher's preferences. He suggests that still much research remains to be done on the issues such as how individual differences play out at the highest levels of proficiency and in what are the ways in which teachers as well as program administrators could be trained in order to make healthier use of learners' individual differences 
(Ehraman, Leaver, \& Oxford, 2003)

\section{Method}

The study is planned to be done under the positivist and systematic paradigm that is quantitative in its approach and its co relational in its kind to determine the relationship between self-esteem as an independent variable and Oral proficiency in ESL as a dependent variable. The researchers have strategized to select those samples, measuring instruments, design and procedures, which favorably enabled them to collect the desired data, necessary to test the statement being hypothesized. The results and effects gathered from the findings would indicate either support or refute the hypothesis with respect to the particular participants, context given, and the instruments involved. The results might be generalized to all ESL learners.

Self-esteem as an affective variable was of main focus is a quantitative variable existing in the form of degree (more or less) and therefore the researcher needed a statistical analysis for its data. The data was collected through tests and observations. The selected target population representing the whole population of ESL learners consisted of different departments from SBK women's University; Baluchistan but the sample comprised of 30 students Masters Students who were simultaneously enrolled in a language course. The researcher planned to select them as her research participants in accordance with the requirement of her study. Besides their curriculum of master studies, these participants had more interaction with English language and were hoped to provide the researcher with the needed data.

\subsection{Theoretical Framework}

Krashen (1982), "Five hypotheses of Second Language Acquisition" are the most influential hypotheses in all areas of second language research and pedagogy since the 1980s. Namely these hypotheses are "the Acquisition-Learning hypothesis", "the Monitor hypothesis", "the Natural Order hypothesis", "the Input hypothesis", and "the Affective Filter hypothesis".

"The Affective Filter hypothesis" served as a theoretical framework for this study. The researcher focused only on the fifth hypothesis in which Krashen hypothesizes that an imaginary barrier of affective factors in learner prevents him/her to acquire the target language. In other words, if the affective filter of learner is "down", it enhances second language acquisition and if it is "up", it hinders second language acquisition. This hypothesis clearly states that there are number of affective variables which play a facilitative role in second language acquisition, but it doesn't claims any causal role of these variables in second language acquisition. These variables comprise motives, needs, attitudes and emotional states. Strictly speaking emotional state involves Self- Esteem, anxiety and motivation. They all may affect second language acquisition. When the learners' self-confidence and self-concept are not optimal for second language acquisition, the affective filter blocks the input, preventing it to reach that part of the brain responsible for language acquisition and consequently, even if learners do receive proper information yet this given input will serves of no use for the desired acquisition process.

In the context of researcher's own study, Krashen views are interpreted as that ESL learners with high Self-Esteem and a positive self-image is more likely to use input for second language acquisition because their affective filter is lowered. Whereas Low self-esteem raises their affective filter preventing ESL learners from using comprehensible input for second language acquisition i.e., the avoidance of opportunities to excel their language oral proficiency.

The selected instrument to measure the desired variables was according to suitability to variables type. For a variable of Self-Esteem researcher had selected an online version Rosenberg Self-Esteem Scale (SES). This scale is a Likert scale consisting ten items with answered on a four point scale ranging from strongly agree to strongly disagree. The scale was initially developed in 1960s for the sample comprising 5,024 High School juniors and seniors that were randomly selected from 10 schools in New York State.

Researcher had designed rubric herself to collect data about the second variable i.e., "ESL Oral Proficiency", and arranged a tape recorder through which she could get the voiced sample. She recorded the gathered data through narrated and scale method. While observing she filled rubric about participants speaking skill simultaneously recording their voices and soon after the completion of this task, the rubric marking were checked by listening once again to the recorded data she intended to recheck her rubric marking by listening once again to the recorded data.

\subsection{Data Collection}

As method adopted by researcher was non-participant controlled observation, so she asked language teachers for cooperation and assistance and fortunate enough they courteously arranged classes for her. Participants were selected from three different departments: Botany, Economics and Education. The teacher asked students to present the topic which was mentioned in the rubric and also read note given at the top of rubric in front of the class in order to inform them about researcher's intention as well as the purpose of the whole activity. While observing 
participants' performance, researcher recorded their voices as well. Researcher side by side filled rubric of every participant and to ensure her observation to be accurate, she also distributed rubric among language teachers who were assisting her at the time of the whole process of data collection. As the topic was given to the participants at the spur of moment, non-proficient speakers and less proficient speakers mostly left their presentation before the time limit without the utilization of their speaking skills. But proficient speakers were quite good in their oral performance.

Among the selected participants who were willing to present the topic, they were asked latter on to test too their level of self-esteem on Rosenberg Self-Esteem Scale. They were required to select a choice, which best suited their characteristics in their view. In order to ensure the participants' understanding of the given items in the scale, a brief explanation was provided to them by researcher, which enabled participants to understand the items clearly. The score attained by each participant was noted down by researcher.

After the data has been entirely collected, researcher compared her rubric total marks of each participant once again with the recorded voice of every participant. Now the researcher was more confident about her rubric results as they were tested and checked thrice. This whole process of data collection took almost three days; one department per day, as researcher by the cooperation of language teachers teaching at SBK Woman's University, was able to get daily one hour period of English class in each department.

\subsection{Validity and Reliability}

The researcher has made an attempt to make her instrumentation valid and reliable by selecting an appropriate already developed standardized test i.e. online version Rosenberg Self-Esteem Scale (SES) so that scores obtained from this test remains alike if the test is re administered on same sample at another time or with different participants by another researcher. Since this scale purely measures the self-esteem and is not culture-bound. Therefore it is used as a content-free measure. Greenwald \& Farnham in 2000, persuasively stated that regardless of some potential shortcomings of explicit self-report measures, studies can be confidently carried out by using such explicit measures and among these self-esteem measurements, the Rosenberg scale, has been shown to be highly reliable; e.g., if someone would chose the options on scale on two different conditions, still the two scores obtained independently each time look parallel. Gray et al. (1997) refer to this scale as a highly valid one because it is uni-dimensional. For the validity of researcher's own designed rubric for oral proficiency, rubric was modeled on the criteria put forward by IELTS (International English Language Testing System), CPE (Certificate of Proficiency in English), and CELS (Certificate in English Language Skills) Hughes (2016). The rubric consisted of 6 items. The total possible score on the scale ranged from 0 to 30, with 30 highest score possible on the rubric indicated higher levels of ESL oral proficiency, while scores within the range of 15 to 25 were considered as normal level of oral proficiency and scores below 15 were regarded as the indication of poor oral proficiency and to confirm its reliability, marks awarded to participants on the basis of their oral performance were checked thrice by researcher herself with the help of recorded voices and language teachers' assistance.

\subsection{Rosenberg Self-Esteem Scale (SES)}

The other instrument used to assess the individual self-esteem was the Rosenberg Self-Esteem Scale (Rosenberg, 1965) (see Appendix A). This scale is widely used for measuring one's Self-Esteem and consists of 10 items with a 4- point Likert scale ranging from strongly agree to strongly disagree. Since this scale purely measures the self-esteem and is not culture-bound. Therefore it was used as a content-free measure and served the purpose of the present study. This scale also ranged from 0-30, with 30 highest score possible. Higher scores on the scale indicated higher levels of Self-Esteem, while scores within the range of 15 to 25 were characterized as normal level of oral proficiency and score below 15 to 0 were categorized as low or poor level of Self-Esteem. To score the items, a value was assigned to each of the 10 items as follows:

- For items 1, 2, 4, 6, 7: $\mathrm{S} \mathrm{A}=3, \mathrm{~A}=2, \mathrm{D}=1$, and $\mathrm{S} \mathrm{D}=0$.

- For items $3^{* *}, 5^{* *}, 8^{* *}, 9^{* *}, 10^{* *}: \mathrm{S} \mathrm{A}=0, \mathrm{~A}=1, \mathrm{D}=2$, and $\mathrm{S} \mathrm{D}=3$.

These items were given with the asterisks**, indicating that they were reversed in valence.

\subsection{Rubric Formation}

The Rubric for ESL Oral Proficiency was designed to analyze two major areas of speaking that are fluency and accuracy (see Appendix B). The components which were held under consideration of each area are:

\subsubsection{Fluency}

a. Level of hesitancy* $=6$ to 0 ; where very Low $=6$ and very high $=0$ (The asterisk shows inverse marking).

b. Speed of speaking $=0$ to 6 ; where very good $=6$ and very poor $=0$. 
c. Utilization of given time limit $=0$ to 3 ; where very good $=3$ and very poor $=0$.

\subsubsection{Accuracy}

a. Pronunciation $=0$ to 6 ; where very good $=6$ and very poor $=0$.

b. Grammar usage and syntactical organization $=0$ to 6 ; where very good $=6$ and very poor $=0$.

c. Range of vocabulary $=0$ to 3 ; where very good $=3$ and very poor $=0$.

"Level of hesitancy" and "Speed of speaking" were regarded as main body of fluency while "Pronunciation" and "Grammar usage and syntactical organization" were viewed as main body of accuracy, therefore these items were awarded 6 scores. Besides these major items other micro items such as "Utilization of given time limit" and "Range of vocabulary" were awarded score 3.

Table 1. Rubrics

\begin{tabular}{l}
\hline Oral proficiency area: Speaker's speaking ability. \\
\hline Presentation topic: English as a global language. \\
Presentation time period: 5 - 10 mints. \\
Speaking abilities to be evaluated: Fluency and accuracy \\
\hline
\end{tabular}

The above table includes overall general information about the rubric, whereas criterion for giving scores to a speaker for each item, was also prescribed beforehand by researcher as:

- Fluency:

a. Level of hesitancy: How fluently speaker speaks in a connected form without errors and repetition of words?

b. Speed of speaking: How rapidly can speaker speak without frequent unnecessary gaps, simultaneously making his/her speech clear and comprehensible for the audience?

c. Utilization of given time limit: How successfully a speaker is in properly occupying the time limit allotted to $\mathrm{him} /$ her for presenting the topic?

- Accuracy:

a. Range of vocabulary: How wide and appropriate is speaker's range of vocabulary?

b. Grammar usage and syntactical organization: To what extent speaker applies correctly different grammatical rules and structures without mistakes or slips, and how efficiently a speaker uses varieties of syntactical structures ranging from simple sentence to complex-structured sentences?

c. Pronunciation: To what degree speaker utters words in accurate way or native-like?

\section{Data Analysis}

\subsection{Comparing Obtained Values of Rosenberg SES with Rubric}

Among thirty participants from whom data was obtained, the total scores of each ESL learner on both SES scale and Rubric are enlisted in the table below:

Table 2. Comparing obtained values of Rosenberg SES with rubric

\begin{tabular}{cll}
\hline No of participants & Level of ESL learner's Self-Esteem $(\mathrm{X})$ & ESL learner's Oral Proficiency Achievement(Y) \\
\hline 1. & 19 & 26 \\
2. & 24 & 27 \\
3. & 27 & 18 \\
4. & 23 & 22 \\
5. & 19 & 20 \\
6. & 19 & 14 \\
7. & 22 & 20 \\
8. & 25 & 19 \\
9. & 22 & 16 \\
10. & 22 & 19 \\
11. & 20 & 19 \\
12. & 21 & 12 \\
13. & 19 & 18 \\
\hline
\end{tabular}




\begin{tabular}{lll}
\hline 14. & 16 & 14 \\
15. & 18 & 12 \\
16. & 22 & 20 \\
17. & 18 & 15 \\
18. & 29 & 21 \\
19. & 28 & 22 \\
20. & 21 & 18 \\
21. & 17 & 19 \\
22. & 16 & 14 \\
23. & 22 & 16 \\
24. & 21 & 19 \\
25. & 21 & 20 \\
26. & 16 & 17 \\
27. & 21 & 16 \\
28. & 19 & 12 \\
29. & 21 & 19 \\
30. & 15 & 12 \\
\hline
\end{tabular}

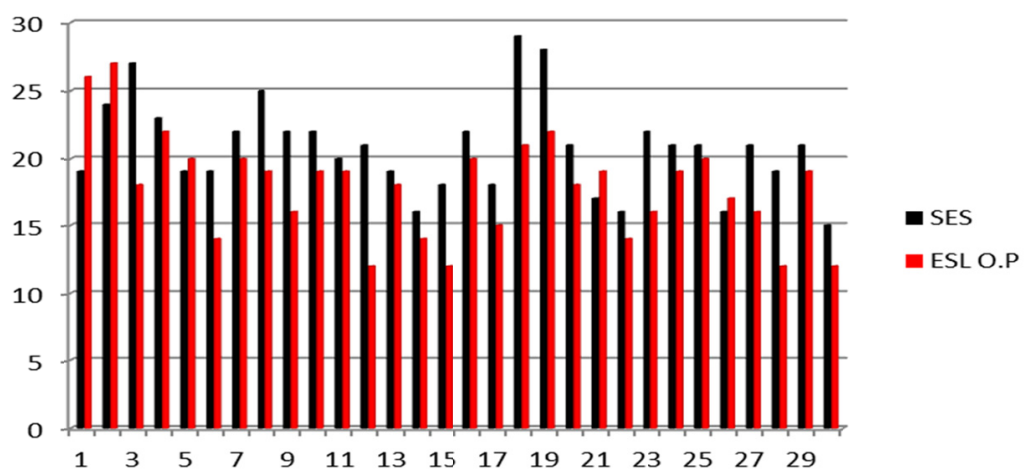

Figure 1. Comparing obtained values of Rosenberg SES with rubric

- $\quad$ SES refers to the value of Self-Esteem of each participant on Rosenberg Self-Esteem scale

- ESL O.P refers to the value of ESL Oral Proficiency of each participant in accordance with the rubric.

- Comparing the two scores of each participant, researcher has come to know that majority of the participants scored under the normal range of Self-Esteem, except two participants with high self-esteem. Coincidently on the basis of marks obtained on the rubric, these participants were also categorized under the normal range of oral proficiency with some variations as well. Among thirty participants, two were highly proficient and five had low oral proficiency level

\subsection{Statistical Analysis of Data}

Statistical computation of a simple relation existing between the two variables is done through correlational analysis. The relationship between two variables implies that the variables influence each other. This influence does not imply a causal relationship. The strength of the relationship is indicated by a correlation coefficient " $r$ " which is a value ranging from \pm 1.00 to 0 . The value with +1.00 determines that strength of relationship between the two variables is strong, while a value in -1.00 indicates a weak relation between the two variables and a correlation equal to zero means that no relation exists between the two variables. A correlation indicates that no relationship rather the two scores vary independent of one another.

The direction of a relationship is either positive or negative where positive direction implies that the scores tend to vary directly; the more an independent variable increases, the more is increase in the dependent variable, and negative direction an inverse relationship indicating that if an independent variable decreases, the other one also decreases. A negative relationship implies that the two variables co-vary in different directions. These positive and negative correlations refer to linear relationships, shown through "scatter gram". This graph is a quick visual interpretation of the relationship between the variables but such graph is limited in detail as it cannot quantify the correlation. Researcher has computed her data quantitatively with the help of correlational coefficient Pearson $r$ formula; 


$$
\text { - } r=\frac{\sum(x-\bar{x})(y-\bar{y})}{\sqrt{\left[\sum(x-\bar{x})^{2}\right]\left[\sum(y-\bar{y})^{2}\right]}}
$$

Where:

$\mathrm{r}=$ Sample correlation coefficient

$\mathrm{n}=$ Number of individuals in the sample/ sample size.

$\mathrm{x}=$ Value of the independent variable

$\mathrm{y}=$ Value of the dependent variable

Table 3. Computing the correlation

\begin{tabular}{|c|c|c|c|c|c|c|c|}
\hline No & $x$ & $y$ & $(x-\bar{x})$ & $(y-\bar{y})$ & $(x-\bar{x})^{2}$ & $(y-\bar{y})^{2}$ & $(x-\bar{x})(y-\bar{y})$ \\
\hline 1. & 19 & 26 & -1.76 & 8.14 & 3.0976 & 66.2596 & -14.3264 \\
\hline 2. & 24 & 27 & 3.42 & 9.14 & 10.4976 & 83.5396 & 29.6136 \\
\hline 3. & 27 & 18 & 6.24 & 0.14 & 38.9376 & 0.0196 & 0.8736 \\
\hline 4. & 23 & 22 & 2.24 & 4.14 & 5.0176 & 17.1396 & 9.2736 \\
\hline 5. & 19 & 20 & -1.76 & 2.14 & 3.0976 & 4.5796 & -3.7664 \\
\hline 6. & 19 & 14 & -1.76 & -3.86 & 3.0976 & 14.8996 & 6.7936 \\
\hline 7. & 22 & 20 & 1.24 & 2.14 & 1.5376 & 4.5796 & 2.6536 \\
\hline 8. & 25 & 19 & 4.24 & 1.14 & 17.9776 & 1.2996 & -4.8336 \\
\hline 9. & 22 & 16 & 1.24 & -1.86 & 1.5376 & 3.4596 & -2.3064 \\
\hline 10. & 22 & 19 & 1.24 & 1.14 & 1.5376 & 1.2996 & 1.4134 \\
\hline 11. & 20 & 19 & -0.76 & 1.14 & 0.5776 & 1.2996 & -0.8664 \\
\hline 12. & 21 & 12 & 0.24 & -5.86 & 0.0576 & 34.3396 & -1.4064 \\
\hline 13. & 19 & 18 & -1.76 & 0.14 & 3.0976 & 0.0196 & -0.2464 \\
\hline 14. & 16 & 14 & -4.76 & -3.86 & 22.6576 & 14.8996 & 18.3736 \\
\hline 15. & 18 & 12 & -2.76 & -5.86 & 7.6176 & 34.3396 & 16.1736 \\
\hline 16. & 22 & 20 & 1.24 & 2.14 & 1.5376 & 4.5796 & 2.6536 \\
\hline 17. & 18 & 15 & -2.76 & -2.86 & 7.6176 & 8.1796 & 7.8936 \\
\hline 18. & 29 & 21 & 8.24 & 3.14 & 67.8976 & 9.8596 & 25.8736 \\
\hline 19. & 28 & 22 & 7.24 & 4.14 & 52.4176 & 17.1396 & 29.9736 \\
\hline 20. & 21 & 18 & 0.24 & 0.14 & 0.0576 & 0.0196 & 0.0336 \\
\hline 21. & 17 & 19 & -3.76 & 1.14 & 14.1376 & 1.2996 & -4.2864 \\
\hline 22. & 16 & 14 & -4.76 & -3.86 & 22.6576 & 14.8996 & 18.3736 \\
\hline 23. & 22 & 16 & 1.24 & -1.86 & 1.5376 & 3.4596 & -2.3064 \\
\hline 24. & 21 & 19 & 0.24 & 1.14 & 0.0576 & 1.2996 & 0.2736 \\
\hline 25. & 21 & 20 & 0.24 & 2.14 & 0.0576 & 4.5796 & 0.5136 \\
\hline 26. & 16 & 17 & -4.76 & -0.8 & 22.6576 & 0.7396 & 3.808 \\
\hline 27. & 21 & 16 & 0.24 & -1.86 & 0.0576 & 3.4596 & -0.4464 \\
\hline 28. & 19 & 12 & -1.76 & -5.86 & 3.0976 & 34.3396 & 10.3136 \\
\hline 29. & 21 & 19 & 0.24 & 1.14 & 0.0576 & 1.2996 & 0.2736 \\
\hline \multirow[t]{3}{*}{30.} & 15 & 12 & -5.76 & -5.86 & 33.1776 & 34.3396 & 33.7536 \\
\hline & $\sum x$ & $\sum y=536$ & & & $\sum \quad(x-\bar{x})^{2}$ & $\sum(y-\bar{y})^{2}$ & $\sum(x-\bar{x})(y-\bar{y})$ \\
\hline & $=623$ & & & & $=383.7584$ & $=421.468$ & $=184.115$ \\
\hline
\end{tabular}

Researcher enlisted all the participants in one column by counting them with serial numbers and the next column in front of every participant, she placed those scores which they obtained on Rosenberg self-esteem scale. In the third column, she noted down Oral Proficiency score of each participant which were awarded to participants on the basis of measures already set in the rubric.

In present study, Self-Esteem was hypnotized as an independent variable which influences ESL Oral Proficiency; therefore Self-Esteem was marked as " $x$ " whereas ESL Oral Proficiency was being considered adependent variable on self-esteem was marked as " $y$ ".

The next step which researcher followed was to separately sum up the total marks of all 30 participants in each column and total obtained values were noted down at the end of each column by using summation symbol " $\Sigma$ " along with each variable $x$ and $y$ 
$\sum x=623$ (Self-Esteem of ESL Learner.)

$\sum y=536$ (Oral Proficiency of ESL Learner.)

Now mean value $(\bar{x}$ and $\bar{y})$ of each summed up value $\left(\sum x\right.$ and $\left.\sum y\right)$ was calculated by dividing each summed up value with total Nth maximum number of the scores present on both SES and Rubric as;

$x=\sum x / \mathrm{n}=623 \div 30=20.76$

$\bar{y}=\sum y / \mathrm{n}=536 \div 30=17.86$

Summation of values was computed as:

$\sum(x-\bar{x})^{2}=383.7584$

$\sum(y-\bar{y})^{2}=421.468$

$\sum^{\prime}(x-\bar{x})(y-\bar{y})=\mathbf{1 8 4 . 1 1 5}$

After getting all the calculated values, they were put in the correlational coefficient Pearson $r$ formula and the final value of " $r$ " was figured out as;

$\mathrm{r}=0.5$

Correlation coefficient rages from -1 to 1 , since researcher's result is 0.5 this value implies that two variables have a moderate positive correlation.

Plotting Values on scatter gram:

A graph below shows correlation between bivariate data i.e., Self-esteem and ESL Oral proficiency.

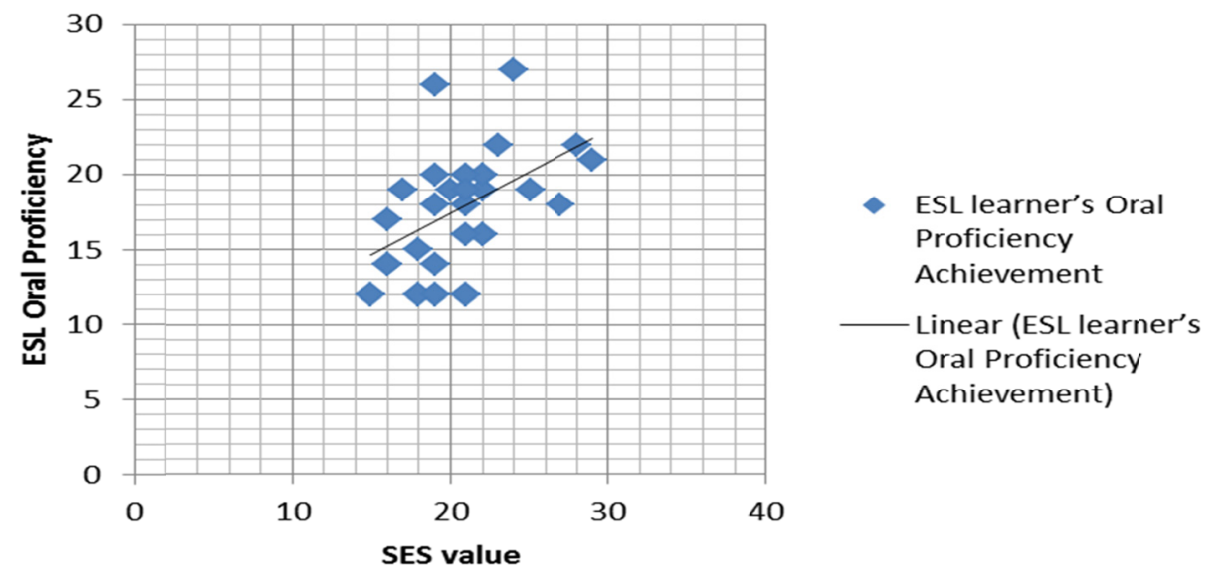

Figure 2. Correlation between bivariate data i.e., self-esteem and ESL oral proficiency

\section{Results}

There was a significant correlation between ESL learner's Self-Esteem and his/her ESL Oral Proficiency, $r=+0.5$, $<+00.1$. This is moderate value of coefficient indicating a positive directional but not exactly a linear one. This correlation indicates that majority of ESL learners with high Self-esteem tend to have better "Oral Proficiency" than those with low Self-esteem. The scatter gram of the given values shows a curvilinear path which points out that there exist a significant positive direct relation between the two variables

\section{Conclusions}

Her main purpose of the study was to explore the following objectives:

- To determine the extent of Self-Esteem's role as an affective factor in second language process

- To compare the ESL learner's Self-Esteem level to his/her achievements in Second Language Oral Proficiency.

As with respect to the relationship between ESL learners Self-Esteem and their Oral proficiency, a positive and significant correlation was found in this study, so it can be concluded that Self-Esteem is an important affective factor that plays role in learner's ESL Oral Proficiency Achievement. This fulfills the first research objective of 
the study. There was a moderate interdependency between these two variables where mostly of the ESL learners' self-esteem score fall in to the normal range so do their level of ESL Oral Proficiency. The statistical value is also significant in debating that besides cognitive aspects, Self-esteem is not the only and merely affective factor involved in ESL learners' Oral Proficiency, rather along with the learners' self-esteem many other affective factors are responsible for language proficiency achievements such as anxiety, stress, motivation and inhibition.

These findings asserted the applicability of Krashen's Affective Filter Hypothesis as well affirmed researcher own hypothesis in the present study. Hence the objectives and goals of the research were successfully achieved.

\section{Implications}

The findings in this study indicate that besides peripheral factors including family, teachers, peers, and community, Learners own role is important to have their self-esteem developed. Leaner's cognition domain and other intrinsic affective factors are foundation elements in the attainment of language oral Proficiency. It is only with the positive influence of Self-esteem that enables learners to participate actively and productively in the ESL learning activities such as debates, discussions, conversations, presentations and interviews required to excel their Language Oral proficiency. The first implication of this study is that ESL learner themselves need to be aware of the importance of developing positive Self-esteem in order to achieve ESL Oral Proficiency. Community, home, institute, and companions are also important factors in the assertiveness and growth of students' self-esteem. They all may contribute to build up learners' self-esteem and provide ESL learners with comprehensible input, but despite cognitive factors of human personality and all these external and Learner's affective factors do pay a vital role in language acquisition process and among these affective factors, learners owns self-belief and level of Self-esteem has influential role too.

Another implication of this study is that self-esteem might vary according to the experiences in the language learning environment. Therefore, language teachers must be facilitators in an atmosphere where the students feel they are respected and worthy rather than having developed feelings of being non self-worthy and a failure. Educators need to be aware of, not only the cognitive domain, but also the affective domain involved in ESL learners' process of acquisition and achievements. If the teacher is not aware of the students' feelings, needs, emotions and willingness to communicate, learners' ESL oral Proficiency will be adversely affected. Thus ESL teachers' chief concern should be the establishment of a classroom environment which promotes open communication and, at the same time improves the levels of self-esteem of their learners. High self-esteem produces confidence which allows learners to develop a desire to communicate.

\section{Recommendations}

The findings and implications of this research study have permitted the researcher to offer the subsequent recommendations.

- Self-esteem might vary according to the experiences in the language learning environmental factors including family, teachers, peers, and community; ESL learner's self-esteem can be upgraded more efficiently, if they all in general, team up to enhance positive communications irrespective of individual or cultural differences and provide the opportunities for ESL learner's to believe in their worth as competent learners. The teachers of English language should keep themselves abreast of the latest innovations in the teaching methodologies and strategies which can make ELT more meaningful and functional in professional education.

- At every educational level such curriculums should be designed which strengthen and reinforce learning in meaningful contexts simultaneously encouraging learners' affective domain in the ESL classroom. Courses such as English Language Skills, Technical Report Writing, Business Communication, Effective Speaking etc., should be an important part of the course which are not only essential for learning a target language, but also helps the students to learn how to communicate effectively their ideas, facts, feelings, attitudes and course of action to others in their future professional careers.

\section{References}

Branden, N. (1969). The psychology ofself-esteem. New York: Bantam Books.

Brown, H. D. (1994). Principles of language learning and teaching. Englewood Cliffs, N.J: Prentice Hall Regents.

Cooper, C. (2002). Individual Differences (2nd ed.). London: Arnold.

Coopersmith, S. (1967). The antecedents of self-esteem. San Francisco: W.H. 
Demo, D. H., \& Parker, K. D. (1987). Academic achievement and self-esteem among Black and White college students. The Journal of Social Psychology, 127(4), 345-355. https://doi.org/10.1080/00224545.1987.9713714

Deutsch, M., \& Solomon, L. (1959). Reactions to evaluations by others as influenced by self-evaluations. Sociometry, 22(2), 93-112. https://doi.org/10.2307/2786014

Donald, A., Jacobs, L. C., \& Christine, K. S. (n. d.). Introduction to Research in Education (8th ed.). 2010, 2006 Wadsworth, Cengage Learning.

Dörnyei, Z. (2006). Individual differences in second language acquisition. AILA Review, 19(1), 42-68.

Ehrman, M. E., Leaver, B. L., \& Oxford, R. L. (2003). A brief overview of individual differences in second language learning. System, 31(3), 313-330. https://doi.org/10.1016/S0346-251X(03)00045-9

Gay, L. R. (1999). Educational research. Upper Saddle River, New Jersey: Prentice Hall.

Graham, M. P. (1993). Language Learning Strategies: What Every Teacher Should Know. Rebecca L. Oxford. Tesol Quarterly, 27(1), 121-122. https://doi.org/10.2307/3586958

Gray, L. B., Williams, V. S., \& Hancock, T. D. (1997). An item response theory analysis of the Rosenberg Self-Esteem Scale. Personality and Social Psychology Bulletin, 23(5), 443-451. https://doi.org/10.1177/0146167297235001

Greenwald, A. G., \& Farnham, S. D. (2000). Using the implicit association test to measure self-esteem and self-concept. Journal of Personality and Social Psychology, 79(6), 1022. https://doi.org/10.1037/0022-3514.79.6.1022

Hayati, A. M., \& Ostadian, M. (2008). The relationship between self-esteem and listening comprehension of EFL students. Published Research, Faculty of Letters and Humanities, Shahid Chamran University of Ahvaz, Iran, 1-13.

Heyde, P. A. (1983). Self-esteem and the acquisition of French. Second Language Acquisition Studies (pp. 175-187). Newbury House, Rowley, MA.

Higgins, E. T. (1996). The "self digest": self-knowledge serving self-regulatory functions. Journal of Personality and Social Psychology, 71(6), 1062. https://doi.org/10.1037/0022-3514.71.6.1062

Hughes, R. (2016). Teaching and researching speaking. Abingdon-on-Thames: Taylor \& Francis.

Krashen, S. D. (1982). Child-Adult Differences in Second Language Acquisition. Series on Issues in Second Language Research: Newbury House Publishers.

Little, R. E. (1975). Manual on statistical planning and analysis for fatigue experiments (Vol. 588). ASTM International. https://doi.org/10.1520/STP588-EB

Nogueras, C. R. H., \& Rosa, C. (1996). Self-esteem and oral communicative language proficiency in the Puerto Rican teaching-learning process. Doctoral dissertation, Inter American University of Puerto Rico.

Nunan, D., \& Carter, R. (Eds.). (2001). The Cambridge guide to teaching English to speakers of other languages. Ernst Klett Sprachen.

Ritak K, B. P. (2000). Personal Psychology for life and work. New York: McGraw-Hill.

Rosenberg, M. (1965). Society and the Adolescent Self-image. NJ: Princeton University Press. https://doi.org/10.1515/9781400876136

Rubio, R. A. (2007). Self-esteem and foreign language learning. Cambridge: Cambridge Press. 


\section{Appendix A}

Rosenberg Self-Esteem Scale (SES)

\begin{tabular}{|c|c|c|c|c|c|}
\hline \multicolumn{6}{|c|}{ Rosenberg Self-Esteem Scale(SES) } \\
\hline & Name; & 1. & & & 4. \\
\hline \multirow{2}{*}{\multicolumn{2}{|c|}{ Department and Semester; }} & STRONGLYA & AGREE & DISAGREE & STRONGLY \\
\hline & & GREE & & & DISAGREE \\
\hline 1. & $\begin{array}{l}\text { I feel that I'm a person of worth, at least on an equal plane } \\
\text { with others. }\end{array}$ & SA & $\mathbf{A}$ & D & SD \\
\hline 2. & I feel that I have a number of good qualities. & SA & $\mathbf{A}$ & D & SD \\
\hline 3. & All in all, I am inclined to feel that I am a failure. ** & SA & $\mathbf{A}$ & D & SD \\
\hline 4. & I am able to do things as well as most other people & SA & $\mathbf{A}$ & D & SD \\
\hline 5. & I feel I do not have much to be proud of. ** & SA & $\mathbf{A}$ & D & SD \\
\hline 6. & I take a positive attitude toward myself. & SA & $\mathbf{A}$ & D & SD \\
\hline 7. & On the whole, I am satisfied with myself. & SA & $\mathbf{A}$ & D & SD \\
\hline 8. & I wish I could have more respect for myself. ** & SA & $\mathbf{A}$ & D & SD \\
\hline 9. & I certainly feel useless at times. $* *$ & SA & $\mathbf{A}$ & D & SD \\
\hline 10. & At times I think I am no good at all. ** & SA & $\mathbf{A}$ & D & SD \\
\hline
\end{tabular}

\section{Appendix B}

ESL Oral Proficiency

Rubric For ESL Oral Proficiency:

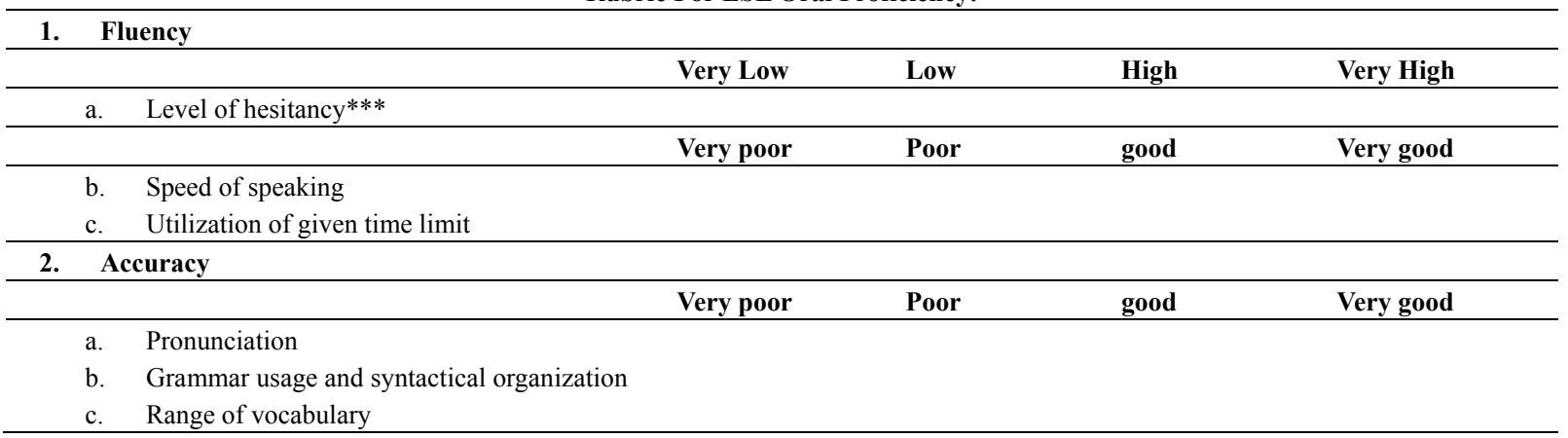

\section{Copyrights}

Copyright for this article is retained by the author(s), with first publication rights granted to the journal.

This is an open-access article distributed under the terms and conditions of the Creative Commons Attribution license (http://creativecommons.org/licenses/by/4.0/). 